(c) American Dairy Science Association, 2004.

\title{
Letter to the Editor: Plea for Using the Term n-7 Fatty Acids in Place of C18:2 cis-9, trans-11, and C18:1 trans-11 or Their Trivial Names Rumenic Acid and Vaccenic Acid Rather than the Generic Term Conjugated Linoleic Acids
}

\author{
G. Ellen ${ }^{1}$ and A. Elgersma ${ }^{2}$ \\ ${ }^{1} \mathrm{NIZO}$ food research \\ PO box 20, 6710 BA Ede, The Netherlands \\ ${ }^{2}$ Department of Plant Sciences \\ Wageningen University, Haarweg 333, \\ 6709 RZ Wageningen, The Netherlands
}

Starting in the 1990s, an ever-increasing number of papers about conjugated linoleic acid (CLA) are published yearly. From 1999 on it has become clear that different CLA isomers have different physiological effects (Martin and Valeille, 2002). Consequently, when referring to CLA in general, and to CLA in milk fat in particular, it would be better to clearly state which isomer is meant. For milk, "C18:2 cis-9, trans-11" or "rumenic acid" is the main isomer, and this term should be used in preference to CLA. It can be foreseen that the term CLA might be associated with negative health effects, as a result of the liver-fattening and liver-enlarging effects of CLA trans-10, cis-12 found in experimental animals (De Deckere et al., 1999; Warren et al., 2003). This could negatively influence the health image of dairy products.

Similarly, for "C18:1 trans-11" the name "vaccenic acid" could be used to avoid negative associations with trans fatty acids in general.

Rumenic acid and vaccenic acid have similar, positive health effects. Because rumenic acid and vaccenic acid

Received December 30, 2003.

Accepted February 27, 2004.

Corresponding author: Anjo Elgersma; e-mail: anjo.elgersma@ wur.nl. are both omega-7, or n-7 fatty acids, which are naturally present almost only in milk and meat from ruminants, it could be advantageous to refer to them as n-7 fatty acids, or use their individual trivial names, in order to avoid confusion with other CLA isomers or trans fatty acids.

Other $\mathrm{n}-7$ fatty acids occur only sparsely in fats and oils (http://msdlocal.ebi.ac.uk/docs/chem_comp/fatty_ acids.html), and their physiological effects are not well documented. Because these rare fatty acids are almost absent in the human diet, the term n-7 fatty acids would be appropriate to characterize rumenic and vaccenic acid as highly interesting components with positive health effects in milk fat.

\section{REFERENCES}

De Deckere, E. A. M., J. M. M. Van Amelsvoort, G. P. McNeill, and P. Jones. 1999. Effects of conjugated linoleic acid isomers on lipid levels and peroxisome proliferation in the hamster. Br. J. Nutr. 82:309-317.

Martin, J-C., and K. Valeille. 2002. Conjugated linoleic acid: All the same or to everyone its own function? Reprod. Nutr. Dev. 42:525-536.

Warren, J. M., V. A. Simon, G. Bartolini, K. L. Erickson, B. E. Mackey, and D. S. Kelley. 2003. Trans-10, cis-12 CLA increases liver and decreases adipose tissue lipids in mice: Possible roles of specific lipid metabolism genes. Lipids 38:497-504. 